\title{
INTRODUÇÃO À ENGENHARIA: UMA PROPOSTA ENVOLVENDO UM PROJETO ARTICULADOR NO CICLO BÁSICO
}

\author{
AN INTRODUCTION TO ENGINEERING: A \\ PROPOSAL INVOLVING AN ARTICULATING \\ PROJECT FOR THE FIRST YEARS OF THE \\ CURRICULUM
}

Wagner Marcelo Pommer*

\section{RESUMO}

Este relato discute e apresenta algumas possibilidades que a disciplina Introdução à Engenharia pode acrescentar ao ciclo básico. Uma prerrogativa essencial dessa inclusão curricular é promover a articulação entre as disciplinas, especialmente por intermédio da concepção de um projeto educativo. Ilustramos uma viabilização desta modalidade didática - um projeto articulador - desenvolvido com alunos ingressantes do curso de engenharia, como importante via de acesso que permite explorar a conexão inerente ao par conhecimento \& competência.

Palavras-chave: Projeto educativo. Engenharia. Ciclo básico. Conhecimento \& competência.

\begin{abstract}
This paper discusses the possibilities that may be added to the first years of the engineering curriculum by the course Introduction to Engineering. An essential prerogative involving this curricular inclusion is the articulation between courses through the conception of an educational project. This paper illustrates how this modality can be implemented - by means of an articulating project developed with engineering students as an important form of access that allows the connection between knowledge and competence to be better explored.
\end{abstract}

Keywords: Educational project. Engineering. Basic cycle. Knowledge and competence.

“Doutorado em Educação. FEUSP/Campus São Paulo. E-mail:<wmpommer@usp.br>. 


\section{Uma 'Introdução à Engenharia'}

Usualmente, um aluno ingressante num curso universitário possui poucos conhecimentos em relação aos fatores que a formação acadêmica pode conferir, no caso, ao futuro engenheiro.

Em 2009, pudemos participar da inserção de um projeto educativo destinado a calouros do curso de engenharia, em uma instituição de ensino superior do setor privado. Coube à recém-criada disciplina 'Introdução à Engenharia' receber os alunos ingressantes e promover uma espécie de ritual de aproximação inicial ao mundo do engenheiro.

Em algumas instituições de ensino superior, esta disciplina foi introduzida em meados dos anos 90, nos Estados Unidos, com a paralela publicação de livros para propiciar suporte bibliográfico. Experiência similar ocorreu em algumas universidades públicas brasileiras, como no pioneirismo da Universidade Federal de Santa Catarina, que originou a publicação de material didático. Também surgiram alguns projetos no Instituto Tecnológico de Aeronáutica (ITA) e na Universidade de São Paulo (Poli-USP), dentre outros, porém sem os moldes disciplinares.

Indiretamente, inspirando-se nas experiências precedentes, a proposta da disciplina se pauta em referenciar o universo da engenharia quanto à formação profissional do engenheiro, especialmente em relação à ética profissional. Etimologicamente, ética se origina do grego ethos, termo que revela o modo de ser e caráter do indivíduo. Dessa forma, enfatizamos na disciplina 'Introdução à Engenharia' a discussão da ética em relação ao profissional engenheiro, destacando a paridade do relacionamento profissional\&sociedade, ou seja, do que é bom para o profissional e para a sociedade, no entendimento de se estabelecer a natureza de deveres.

Outro ponto a se destacar no planejamento desta disciplina foi a inclusão da apresentação do processo de evolução e constituição da profissão de engenheiro ao longo da história da civilização. Estendemos esta visão da linha do tempo considerando o perfil dos cursos de engenharia até os dias atuais, destacando como funcionam os organismos reguladores profissionais, como ocorre o processo de estudo e de pesquisa nesta área e também abordando alguns casos que ilustram a peculiar forma de solução de problemas inerentes à efetivação do trabalho de engenharia.

A metodologia de ensino da disciplina consiste em utilizar aulas expositivas pelo professor, aliado a estudos de casos, normalmente referenciados na pouca literatura existente em relação a tal temática.

Em relação às prerrogativas expostas, a disciplina 'Introdução à Engenharia' acrescentou um enfoque didático, promovendo o que denominamos de projeto articulador. Essa ação se constituiu em importante ato de regulação, permitindo aos professores o desenvolvimento de uma ação efetiva, por intermédio da implementação de um projeto, favorecendo importante estratégia de ensino apropriada aos objetivos propostos.

Este tipo de ação didática que defendemos, presente em alguns centros de ensino superior, permite uma solução de continuidade na maneira como as aulas se desenvolvem em relação ao ensino básico, refletindo assim uma preocupação essencial, que consiste em prover condições para o engajamento e preparo dos estudantes para o exercício da profissionalidade e cidadania: o trabalho com projetos favorece as prerrogativas e demandas da atual sociedade globalizada.

Diante dessas considerações, naturalmente emergem algumas ponderações em relação à natureza do conhecimento a ser veiculado no ambiente universitário, de modo a preparar o aluno para as competências necessárias ao mercado de trabalho. Sendo assim, destacamos questões como: Quais mudanças cabem à universidade e como ela pode contrapor dinâmicas para desempenhar um papel pró-ativo, de modo a promover ações de integração em relação aos conhecimentos desenvolvidos em cada disciplina, possibilitando vivências significativas para os alunos? Especificamente, que contribuições as disciplinas do ciclo básico podem prover no preparo acadêmico e profissional dos alunos de cursos de engenharia, principalmente usufruindo de formas didáticas de aulas que gerem autonomia, ações efetivas e reflexivas?

Diante das questões suscitadas, inicialmente destacamos Machado (2001), que aponta o conhecimento como fator imprescindível e primordial para a atual sociedade. O referido autor discute o papel das universidades como importante centro de criação e distribuição do conhecimento, ocupando um cenário de destaque que precisa ser compreendido e aprimorado. 
Machado (2001) destaca que as organizações educacionais pautam as ações no encadeamento cartesiano, que fragmenta e esvazia o significado dos objetos de conhecimento, sem uma contrapartida dos valores envolvidos. Essa posição pode ser observada no discurso educacional dos pré-requisitos necessários, da seriação e estabelecimento de uma rígida ordem necessária para os estudos através do currículo e programas.

Tais diretrizes se acentuam nos cursos do ensino superior que, usualmente, ignoram a diversidade de contextos, de centros de interesse e possibilidades de percursos de abordagem do conhecimento. A perspectiva do encadeamento cartesiano não favorece a formação pessoal, a formação profissional e nem o preparo para o trabalho em equipe, não possibilitando as necessárias interações entre as diversas disciplinas componentes dos currículos dos cursos de graduação.

Em consonância com a posição de Machado (2001), acreditamos na necessidade da reorganização do processo de construção/circulação do conhecimento, referente à estrutura presente nos currículos. Essa proposição não implica a mudança ou extinção do eixo cartesiano, fundamental para a organização educacional e para a formação profissional, com base em um necessário elenco de disciplinas. Porém, quando observamos a preocupação exclusiva das instituições de ensino superior na organização curricular em departamentos, a interação acadêmica fica limitada e se caracteriza certo bloqueio à imprescindível partilha de conhecimentos tácitos a serem desenvolvidos nas diversas disciplinas.

Para favorecer a circulação do saber, Machado (2001) propõe uma organização alternativa, através do desenvolvimento do conhecimento como rede de significações. Neste sentido, conhecer significa estabelecer feixes de relações que permitam aos alunos apreender os significados dos signos que circulam e são construídos socialmente e no seio das diversas linguagens e meios.

Acreditamos que as disciplinas precisam abrir espaço para dialogar, através do conhecimento, com seus pares acadêmicos, de modo a alargar os horizontes culturais. Assim:

A noção do conhecimento como rede conduz a um redimensionamento no papel das disciplinas. A metáfora do mapa, ou da teia disciplinar como um mapeamento para orientar os percursos sobre a rede de significações, precisa ser explorada de modo conseqüente, estimulando-se o livre trânsito entre as diversas fronteiras disciplinares, abertas, flexíveis, em vez de delimitar territórios com um sentido de posse. (MACHADO, 1995, p.23).

Diante da necessidade de aproximar o trabalho acadêmico das atividades de pesquisa e trabalho, Macedo (2006) propõe o projeto como uma ferramenta para se exercer a cidadania e desenvolver o compromisso profissional.

\section{A metodologia do projeto: uma mediação} educacional ao par conhecimento \& competência

É usual, na universidade, o trabalho com projetos nas diversas áreas técnicas, principalmente situados nas fases intermediárias e ao final do curso, visando o aprimoramento do conhecimento específico e a formação individual do futuro profissional.

No entanto, urge a necessidade do estabelecimento e criação de oportunidades para uma maior interação entre os pares, de acordo com as demandas da sociedade moderna. Tendo por entendimento que tais demandas estejam principalmente ligadas à realização de projetos nos diversos campos de atuação do mercado de trabalho, tais situações exigem uma flexibilidade nas múltiplas funções necessárias ao exercício profissional.

Assim, além da importante e fundamental formação específica, uma das funções da universidade é promover a articulação entre os conhecimentos pontuais, fomentando a natural complementaridade entre competências e conhecimentos que se mostra tão veementemente solicitada nos diversos meios profissionais, como no presente caso da área de engenharia.

Frente a tais condições, propomos como modo de abordagem didático um trabalho didático posicionado em projetos educativos, situados no ciclo básico dos cursos de engenharia, metodologia que permite regular e nortear a ação discente e docente, assim como cria ambientação para uma maior articulação interdisciplinar. Nessa etapa inicial de vivência universitária, o trabalho com projetos visa articular conhecimentos e competências essenciais, numa atmosfera de conciliação entre competências, interesses individuais e coletivos. Este tratamento 
visa permitir ao aluno lidar com as incertezas pessoais, profissionais e sociais que naturalmente constituem a fase de ingresso na universidade, além de constituir alicerce para o desenvolvimento pleno do futuro engenheiro.

Etimologicamente, projeto deriva de projetus (latim), particípio passado de projicere, significando um jato lançado para a frente. Boutinet (2002) aponta que na antiga Grécia não havia algo equivalente à concepção de projeto. $\mathrm{O}$ entendimento deste termo se consolidou a partir dos séculos XIV, originado nas formas francesas pourjet e projet, que eram os elementos arquitetônicos presentes nas fachadas de balcões e pilares de construções renascentistas.

A acepção moderna de projeto encena uma dupla conotação. Numa primeira visão, projeto pode ser concebido como a arte de representar o que se deseja propor ou criar, aos moldes do que atualmente creditamos como design. A dimensão criadora do projeto é destacada em Marina (1995), ressaltando as várias conexões que a mente criativa proporciona: selecionar a informação necessária, dirigir o olhar para a realidade, definir as próprias metas, inventar possibilidades e antecipar situações.

Numa segunda versão, um projeto pode ser compreendido pela forma de ação que pode se objetivar, presente no ato e na intencionalidade do que deverá ser feito para atingir as metas concebidas. Nesta concepção, nos referimos a Boutinet (2002), que destaca componentes essenciais para se referendar um projeto.

Para o autor, todo projeto parte da concepção que existe um futuro a ser construído e concretizado, transformado em real a partir de uma intenção. Isso abre espaço para a pessoa acreditar no potencial latente, incentivando ideias que podem se transformar em ato.

Uma característica fundamental dos projetos é a abertura. Por princípio, não é possível se estabelecer ou conhecer previamente e de modo determinístico, se ocorrerá o sucesso. Estamos nos referindo ao componente da incerteza, que pode servir de elemento motivador e estimulador para orientar os vários interesses dos alunos, propiciando ambientação para a busca de soluções.

Deste modo, Boutinet (2002) aponta que o princípio da abertura para o novo e a incerteza dos resultados oportuniza a ação, expressa na inventivi- dade e na intuição do melhor caminho a ser trilhado, abrindo possibilidades para se estabelecer múltiplas conexões e apostar em elementos ousados para a busca de diversas formas de concepção e de sucesso na empreitada.

Em síntese, a concepção educativa de projeto, no ambiente escolar, requer do aluno a necessária reflexão e ação, mobilizando recursos, sob a orientação e tutela do professor. Quanto ao papel do professor, torna-se necessário uma preocupação em acompanhar as diversas etapas de proposição, decisões, desenvolvimento, execução e reavaliação do projeto.

Na concepção de projeto educativo, o professor pode intervir, conforme define Vygotsky (2000), apresentando alguns conhecimentos necessários, porém de modo que os próprios alunos tomem as decisões necessárias, visto que o professor não pode fazer ou viver o projeto pelo aluno.

Quanto às competências que podem ser desenvolvidas pelo aluno, como indivíduo que projeta, destacamos em Machado (2008) o agir e o pensar, que permitem dar significado aos conhecimentos. Tais possibilidades podem ser estendidas também para a ação didática do professor, visto a natureza educacional do projeto em questão.

As intenções expostas colocam aluno e professor em parceria, com papéis claros, delimitados e complementares, estabelecendo um modo de flexibilizar tempo e espaço para concretizar o desenvolvimento de um projeto educativo.

Nesse movimento de compromisso de realização do projeto, ponderamos que a ação e a vontade devem ser conciliadas com a razão em favor dos objetivos. Ao se ter projetos, é necessário haver desconforto e predisposição para a mobilização, há de se ter tolerância para trabalhar e aprender junto, desejando um movimento de transformação como profissional, credenciando e estimulando a ética como ferramenta necessária para o futuro engenheiro.

Machado (2008) escreve que cabe à educação inserir os jovens num quadro social e profissional pré-estabelecido, preservando valores, costumes e conhecimentos já estabelecidos, assim como possibilitar a abertura de possibilidades para o novo, transformando o conhecimento. A busca de equilíbrio presente no par conservação (valores) versus transformação (projetos), duas faces da mesma moeda, permite ao professor e à instituição 
escolar fomentar e viabilizar oportunidades para a construção da articulação entre conhecimentos e competências.

\section{O Projeto educativo em ação: elementos e resultados}

$\mathrm{O}$ ato de inserção de um projeto educativo como elemento central e eixo condutor da disciplina 'Introdução à Engenharia' promoveu um ato de regulação. Destacamos nesse meio didático um importante viés, o modo articulador do projeto, conferindo a intenção de valorização das disciplinas presentes no currículo do ciclo básico das engenharias como fonte de conhecimento e competências, aliado ao estímulo e aprimoramento da integração entre elas.

Os elementos característicos do projeto articulador, em grande parte, foram definidos pela própria Instituição de Ensino Superior. O objetivo do projeto educativo foi conceber e construir um protótipo de um 'veículo autônomo', movido a energia potencial elástica, para participar de uma competição em um local pré-determinado.

Isso representou que o veículo autônomo movido a energia potencial elástica, produto final do projeto, participou de competições envolvendo os outros protótipos desenvolvidos pelos diversos grupos. Cada grupo, formado por quatro a sete alunos, foram avaliados em três aspectos:

a) corrida num percurso pré-determinado, classificados pelo menor tempo gasto;

b) corrida de distância, classificados de acordo com a maior distância percorrida;

c) design do protótipo.

O protótipo de veículo autônomo continha algumas características básicas e restritivas. Uma condição inicial era a massa final do produto, que não poderia exceder quinhentos gramas $(500 \mathrm{~g})$. Quanto ao material empregado, este deveria pressupor uma intenção ambiental com características recicláveis, de modo a não poder ocorrer a utilização de peças pré-produzidas, próprias de carrinhos em miniatura, manufaturados industrialmente, existentes no mercado nacional e importado.

Quanto ao mecanismo de propulsão, a proposta foi a utilização de energia do tipo potencial elástica e, pela caracterização de veículo autônomo, o produto deveria conter um mecanismo disparador, de modo a não ocorrer interferência humana após o início do movimento. Nesses moldes, o mecanismo propulsor deveria ser interno e fixo ao veículo.

Com relação à trajetória, o veículo autônomo deveria permanecer na parte interna de uma pista com largura de cerca de três metros, demarcada no contrapiso de cerâmica de um pátio. Quanto ao número de rodas, foi limitado um mínimo de três rodas, sendo que, durante o deslocamento, todas as rodas deveriam estar constantemente em contato com o solo.

Em síntese, as características (modelo de produto, massa, tipo de energia propulsora, mecanismo disparador, pista e número de rodas) e as restrições do projeto articulador promoveram movimentação e motivação na comunidade universitária, propiciando abertura para a criação de diferentes protótipos, de modo a situar um projeto em ação.

Conforme expresso no planograma da disciplina de 'Introdução à Engenharia', a estruturação temporal permitiu uma introdução teórica em relação a alguns temas interdisciplinares, cuja exposição permitiria a evolução das etapas do projeto.

Com relação à disciplina de língua portuguesa, as contribuições ocorreram em nível de estruturação de um texto, em formato acadêmico, com os registros realizados aos moldes de texto científico padrão, documentado segundo as normas da ABNT, nas versões NBR-6022 (2002), NBR-6023 (2002), NBR-6024 (2002) e NBR-14724 (2002).

Incentivamos os alunos na documentação das diversas etapas de evolução do projeto, inserindo-os na formatação padrão do texto científico. Esta etapa foi denominada memorial, muito comum em trabalhos acadêmicos da área de humanidade. A apropriação desse modo acadêmico visou à constituição de roteiro para estimular o registro do percurso idealizado e realizado pelos diversos grupos, de modo a descrever o processo de desenvolvimento do produto, o que pode contribuir para uma visão interdisciplinar do conhecimento e competências.

Um dos grupos, que obteve 64 metros na corrida a distância, sintetizou no memorial as etapas da concepção e construção do veículo, descrevendo que no primeiro contato com a experiência: 
[...] encontramos algumas dificuldades com relação ao material a ser usado. Já na segunda tentativa, as coisas estavam mais claras para o grupo. Sabíamos como seria nosso carrinho antes mesmo de começar a montar, mas mesmo assim não ficamos satisfeitos com o desempenho. [...] No terceiro protótipo, apresentamos bons resultados, fizemos uma série de testes e várias estimativas, sendo que, todos os resultados superaram nossas estimativas e o desempenho foi excelente. (GRUPO 1).

Um dos itens do projeto consistiu na elaboração de uma relação de materiais utilizados, preferencialmente recicláveis (reutilizados, retrabalhados ou remanufaturados). Os grupos evidenciaram no memorial as diversas escolhas, o que fica exemplificado no seguinte relato:

Todos os itens foram confeccionados pelo nosso grupo de trabalho. O chassi do veículo é confeccionado em Duratex, de espessura de $1 \mathrm{~mm}$, onde na parte traseira foram colocados dois mancais de plástico, por onde passa barra rosqueada de diâmetro $6 \mathrm{~mm}$, utilizada como função de eixo. Nas extremidades há duas rodas com rolamentos que faziam parte de um sistema de esteira rolante e, para garantir o atrito suficiente para movimentar o veículo, foram instalados elásticos na função de pneus. Na parte dianteira há uma roda de polietileno construída para esse propósito, que está presa a um eixo de $6 \mathrm{~mm}$ com buchas de fixação utilizando travamento com parafusos rosca M3. Aproximadamente no centro do veículo está posicionada a trena com um fio de nylon de aproximadamente $5 \mathrm{~m}$ de comprimento. Esse fio é enrolado na roda dianteira fazendo com que a mola da trena seja comprimida. $\mathrm{O}$ veículo é posicionado no chão e a força da mola recolhe o fio de nylon fazendo com que a roda dianteira gire e o veículo mover-se à frente. (GRUPO 5).

Quanto às contribuições da disciplina de expressão gráfica, houve a confecção dos desenhos dos elementos constituintes, com régua e compasso, sem o uso de recursos computacionais. Nesta empreitada, foram efetuados os registros em perspectiva isométrica e nas projeções ortogonais usuais (vista frontal, lateral e superior), comuns neste tipo de trabalho, e uma tabela representativa das escolhas realizadas.

Os temas destacados vincularam a possibilidade de oferecer subsídios aos alunos para promover discussão das ideias que permeiam a prática profissional do engenheiro, associando-as ao planejamento, acompanhamento e execução das diversas etapas do próprio projeto articulador.

No planejamento do trabalho, programamos duas competições preliminares, sem caráter oficial, de modo a estimular o desenvolvimento do produto e incentivar as alterações necessárias. Um dos grupos destacou a validade desta estratégia: "Em virtude da análise de outros veículos apresentados em sala de aula, foi repensado o tipo de mola e construção do veículo, para garantirmos uma maior distância e velocidade" (GRUPO 3).

O projeto envolveu conceitos básicos da física mecânica. Com relação à representação dos conceitos de força de atrito e energia um dos grupos escreveu: "Para projeto e desenvolvimento deste veículo, foram aplicados alguns conceitos físicos englobando duas áreas [...]: a Cinemática Escalar e Dinâmica" (GRUPO 3), conforme expresso na figura 1.

Figura 1 - Representação das energias e força de atrito entre as rodas e o piso.

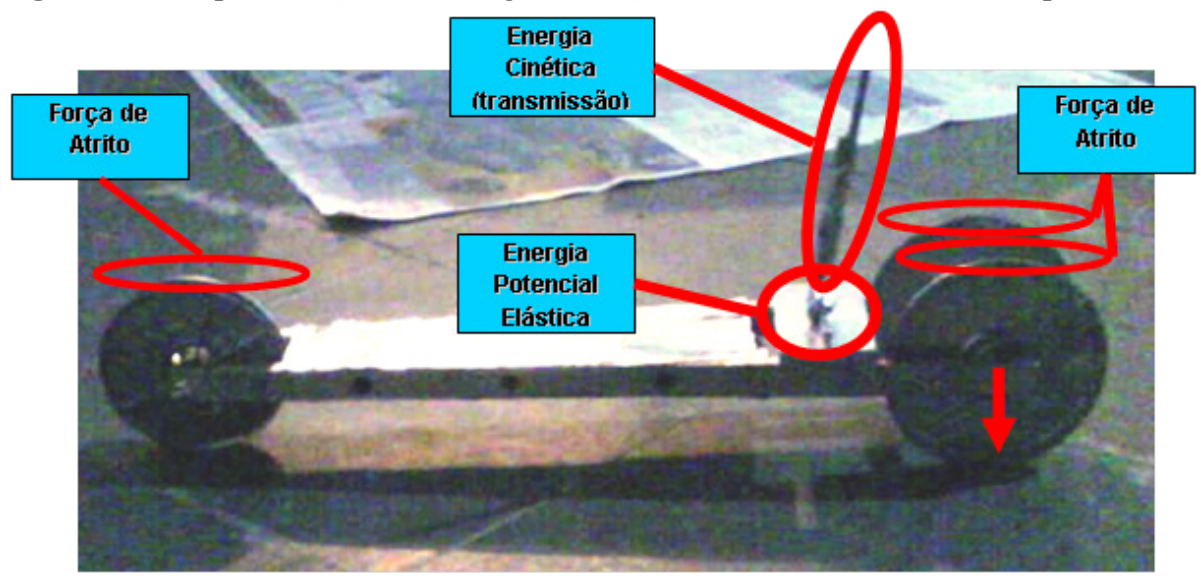

Fonte: Grupo 3 
Houve a descrição e entendimento do tipo de movimento envolvido no movimento, como a percepção na relação entre a natureza da força de atrito entre as rodas e o piso, da força de resistência do ar e o conceito de inércia, de modo que a opção pela busca do protótipo mais eficaz ou adequado propiciou o desenvolvimento de um modelo mais aerodinâmico e que reduziria a ação das diversas resistências.

Fizemos os croquis, e verificamos que o carrinho iria ultrapassar o peso especificado, o que seria um problema, mas como tínhamos tempo, fizemos novas alterações. Logo que terminamos os croquis, começamos a fabricação. No primeiro teste, verificamos que o carrinho não estava alinhado $e$ que gastava muita energia na partida, a ponto de patinar. Tínhamos também que diminuir a área de atrito para que o veículo conseguisse ir mais longe. Para resolver o problema de alinhamento, modificamos os eixos dianteiro e traseiro, mas ainda sim, precisávamos eliminar a perda de energia na partida. Pesquisamos um pouco e conseguimos encontrar uma solução, que seria inserir no projeto um par de engrenagens, com isso, iríamos diminuir o torque e o carrinho não iria patinar Então foi usinado um novo eixo (eixo central), onde a engrenagem maior seria fixada. Como conseqüência o eixo traseiro também sofreu mudanças, pois seria fixado nele uma pequena engrenagem. Feito as mudanças, reduzimos a área de atrito das rodas e consequentemente reduzimos o peso final do carinho. Depois de montado, fizemos os testes, e ficamos surpresos com o resultado, que foi muito satisfatório. (GRUPO 2).

Ainda com relação à disciplina de física, houve incentivo para a realização dos cálculos necessários para antecipar e comparar os valores previstos com os resultados práticos, de modo a regular as decisões a serem tomadas. A disciplina de matemática contribuiu com explicações sobre a dependência, no tópico funções envolvendo duas variáveis, associado às grandezas físicas envolvidas, assim como nas manipulações aritméticas e algébricas.

Os grupos utilizaram basicamente três tipos de sistema propulsor: mola de ratoeira; mola em espiral (mola de relógio, trena ou carrinho de fricção); mola de tração e compressão. Observamos que o sistema de mola com pêndulo não foi utilizado por nenhum grupo. Um único grupo utilizou mola de ratoeira e os demais utilizaram o sistema de mola em espiral (trena).
Detectamos que a mola que tínhamos utilizado possuía pouca força, gerando assim pouca energia, onde necessitaríamos construir uma mola própria ou procurar alguma que apresentasse uma força maior. Pesquisamos em alguns lugares [e] encontramos uma mola de porta de fogão, que preserva o principio inicial. (GRUPO 3).

Também a estratégia de trazer para a sala de aula o trabalho sequencial propiciou aos grupos a antecipação dos vários ajustes que naturalmente se fazem necessários e a inserção de novos elementos, de modo a resolver os problemas oriundos das escolhas realizadas.

Novamente nos reunimos, para iniciar a fabricação/usinagem das peças já desenhadas e definidas. A chapa de alumínio foi cortada e furada. Os eixos $\mathrm{e}$ as rodas foram usinados conforme dimensionamento. O sistema propulsor foi fixado no eixo traseiro conforme necessidade e [para permitir] alinhamento. Logo após a usinagem, começamos a montagem fixando os eixos ao chassi, também foi montado o sistema de trava do chassi e fixação da mola. Para validar o teste físico, verificamos que o projeto alcançou a distância de $36 \mathrm{~m}$ com sucesso. Após teste físico, discutimos [a] necessidade de alterações no projeto. Em 01/05/09, a equipe se reuniu para efetuar as modificações necessárias. [...] Todo o processo de montagem e testes ocorreu no dia seguinte. Tínhamos que diminuir a área de atrito para que o veículo conseguisse ir mais longe. Para resolver o problema de alinhamento, modificamos os eixos dianteiro e traseiro, mas ainda sim, precisávamos eliminar a perda de energia na partida. Pesquisamos um pouco e conseguimos encontrar uma solução, que seria inserir no projeto um par de engrenagens. Com isso, iríamos diminuir o torque e o carrinho [deixaria de patinar]. Então, foi usinado um novo eixo (eixo central), onde a engrenagem maior seria fixada. Como conseqüência o eixo traseiro também sofreu mudanças, pois seria fixado nele uma pequena engrenagem. Feito as mudanças, reduzimos a área de atrito das rodas e conseqüentemente reduzimos o peso final do carinho. Depois de montado, fizemos os testes, e ficamos surpresos com o resultado. (GRUPO 2).

A pesquisa de modelos similares foi realizada em relação aos componentes (mecanismo propulsor, sistema de transmissão de energia), assim como para a concepção de design. Esses modelos serviam de inspiração inicial e geralmente não eram as melhores 
opções. Os alunos, percebendo isso, recriavam com base no mesmo modelo ou reconfiguravam outras ideias como solução.

A carroceria foi projetada com armação de arame trançado e lataria confeccionada com chapas de latinhas de alumino. Após a construção do chassi estaríamos realizando a pintura do mesmo, sendo utilizado primeiramente Primer, como base de pintura e tinta cromada para ressaltar o efeito metálico [...]. O design foi baseado em um avião da força aérea americana, conhecido como Blackbird para os contornos do chassi, sendo que a carroceria foi baseada nos carros conceitos de alta velocidade. (GRUPO 3).

\section{Conclusões}

Inicialmente, destacamos que a inclusão curricular da disciplina 'Introdução à Engenharia' promoveu uma mudança na organização de trabalho. O projeto propiciou o trabalho em conexão das disciplinas iniciais do ciclo básico, o que caracterizou uma importante articulação e comunicação, articulação embasada no princípio de superação do encadeamento cartesiano, favorecendo o desenvolvimento do conhecimento como rede, conforme expressa Machado (1991).

Também ressaltamos a importância da ação dos alunos no desenvolvimento no projeto. Nas aulas, os alunos se organizavam em grupos, discutiam as ideias que surgiam com os colegas, que ora apoiavam ora rejeitavam, mas que caracterizam o caráter de colaboração e cooperação.

Acreditamos ser esta uma manifestação da riqueza semântica da ação, apontada por Machado (2006), pelo labor realizado em conjunto com os colegas, onde se caracterizou a manifestação da vontade livre e consciência, enfim, a liberdade da ação, mas refreada pelos outros elementos do grupo, assim como pelas restrições do projeto.

Outro destaque é para a ação, em virtude do caráter pragmático do projeto em relação à forma e confecção do produto final. A experiência de alguns alunos, que espontaneamente assumiram o comando dos grupos, trouxe para a sala de aula um modo diferente, um viés de prática agregado à rotina acadêmica, que associado à busca de referenciais teóricos, normalmente veiculados pelo ensino superior, ampliou o domínio dos conhecimentos dos alunos e se conectaram ao aprimoramento de competências essenciais ao futuro engenheiro.

$\mathrm{O}$ memorial foi um instrumento importante para o projeto articulador, pela riqueza dos relatos e comentários, que permitiu aos próprios alunos aprimorar a capacidade de expressão na língua portuguesa. Um exemplo disso foi o relato de um grupo, que descreveu a utilização de uma engrenagem para refrear e potencializar o torque inicial, que inicialmente fazia derrapar o carrinho. Em face de tal obstáculo, o grupo expressou que eles utilizaram um tipo de engrenagem que um dos componentes comentou ter observado numa máquina de café expresso, na ocasião em que trabalhava na manutenção dos componentes eletrônicos, neste tipo de equipamento.

Houve dificuldades dos alunos em relação ao tipo de escrita acadêmica. Nesse sentido, a experiência com o projeto permitiu um conhecimento inicial dos trâmites de pesquisa, que podem favorecer os alunos em processos de iniciação científica e no trabalho de conclusão de curso.

Outro aspecto foi a dificuldade dos alunos com os aspectos teóricos, principalmente aqueles oriundos dos conceitos da física. Nesse sentido, as aulas de 'Introdução à Engenharia' serviam como palco de explicações de conceitos elementares de física, ligados à cinemática e à dinâmica: massa, força e energia. Esses tópicos foram analisados de modo a estabelecer relações com os elementos do projeto e que promovessem o conhecimento tácito. Deste modo, percebemos que houve, por parte dos alunos, maior compreensão e relacionamento dos conceitos das diversas disciplinas do ciclo básico. O projeto articulador permitiu um momento de superação de barreiras disciplinares no ensino superior e o fomento para o desenvolvimento de conhecimentos e competências.

Outra contribuição do projeto educativo se situou no terreno da ética, cujos princípios foram desenvolvidos, tanto explicitamente, como ocorreu no estudo de casos e em aulas expositivas, como tacitamente, no decorrer do desenvolvimento do projeto, em analogia com os aspectos respeito, integração e conduta adequada no lidar com os colegas de sala e das outras classes, com o professor e com as regras e diretrizes do projeto. 
Com isso, o projeto viabilizou desenvolver potencialidades nos alunos, que se manifestaram no decorrer do processo de construção dos protótipos e que explicitamente se concretizaram na ação, no pensar e no sentir, visto que o "[...] que caracteriza o olhar inteligente é que aproveita com suprema eficácia os conhecimentos de que dispõe" (MARINA, 1995, p. 35).

Por último, ressaltamos o caráter indissociável entre o par dialético e complementar projeto e jogo, mesmo em situações profissionais, destacado em Macedo (2006). Isso ficou evidenciado neste projeto: "O projeto do carrinho movido à força elástica, tem sido muito interessante. $\mathrm{O}$ fato, é que está despertando nossa imaginação e nossa criatividade, futuros engenheiros, e claro, estamos nos divertindo" (GRUPO 1).

\section{Referências}

ABNT. NBR 6022: informação e documentação, artigo em publicação periódica científica impressa. Rio de Janeiro, ABNT, 2003.

NBR6023: informação e documentação, elaboração e referências. Rio de Janeiro, ABNT, 2002.

. NBR6024: informação e documentação, numeração progressiva das seções de um documento. Rio de Janeiro, ABNT, 2003.

. NBR 14724: informação e documentação, trabalhos acadêmicos e apresentação. Rio de Janeiro, ABNT, 2002.

BAZZO, W. A.; PEREIRA, L. T. V. Introdução à engenharia. São Carlos, Editora da UFSC, 1997.

BOUTINET, J. P. Antropologia do projeto. Porto Alegre: ArtMed, 2002.

MACEDO, L. Jogo e projeto: irredutíveis e complementares. In: ARANTES, A. A. Jogo e projeto. São Paulo: Summus, 2006.

MACHADO, N. J. A Universidade e a organização do conhecimento: a rede, o tácito, a dádiva. Estud. av., São Paulo, v. 15, n. 42, 2001. Disponível em: <http://www. scielo.br/scielo>.

Educação e autoridade. São Paulo: Vozes, 2008.

Epistemologia e didática: as concepções de conhecimento e inteligência e a prática docente. São Paulo: Cortez Editora, 1995.

A vida, o jogo, o projeto. In: ARANTES, A. A.

Jogo e projeto. São Paulo: Summus, 2006.
MACEDO, L. Jogo e projeto: irredutíveis e complementares. In: ARANTES, A. A. Jogo e projeto. São Paulo: Summus, 2006.

MARINA, J. A. Teoria da inteligência criadora. Lisboa: Caminho da Ciência, 1995.

VYGOTSKY, L. S. Pensamento e linguagem. 2. ed. São Paulo: Martins Fontes, 2000. 